\title{
Divergent population trends following the cessation of legal grizzly bear hunting in southwestern British Columbia, Canada
}

\author{
Michelle L. McLellan ${ }^{\mathrm{a}, *}$, Bruce N. McLellan ${ }^{\mathrm{b}}$, Rahel Sollmann ${ }^{\mathrm{c}}$, Clayton T. Lamb ${ }^{\mathrm{d}}$, \\ Clayton D. Apps ${ }^{\mathrm{e}}$, Heiko U. Wittmer ${ }^{\mathrm{a}}$ \\ ${ }^{a}$ School of Biological Sciences, Victoria University of Wellington, P.O. Box 600, Wellington 6140, New Zealand \\ ${ }^{\mathrm{b}}$ British Columbia Ministry of Forests, Lands and Natural Resource Operations and Rural Development, D'Arcy, B.C., Canada \\ ${ }^{c}$ Department of Wildlife, Fish and Conservation Biology, University of California Davis, CA, USA \\ ${ }^{\mathrm{d}}$ Department of Biological Sciences, University of Alberta, Edmonton, AB, Canada \\ e Aspen Wildlife Research Inc., Calgary, AB, Canada
}

\section{A R T I C L E I N F O}

\section{Keywords:}

Population recovery

Brown bear

Pradel robust design

Small population

Ursus arctos

Spatial capture-recapture

\begin{abstract}
A B S T R A C T
We conducted DNA capture-recapture monitoring of grizzly bears (Ursus arctos) from 5 to 17 years after hunting was stopped in two adjacent but genetically distinct populations in southwestern British Columbia, Canada. We used spatial capture-recapture and non-spatial Pradel robust design modelling to estimate population density, trends, and the demographic components of population change for each population. The larger population had 21.5 bears $/ 1000 \mathrm{~km}^{2}$ and was growing ( $\lambda_{\text {Pradel }}=1.02 \pm 0.02 \mathrm{SE} ; \lambda_{\text {secr }}=1.01 \pm 4.6 \times 10^{-5} \mathrm{SE}$ ) following the cessation of hunting. The adjacent smaller population had 6.3 bears $/ 1000 \mathrm{~km}^{2}$ and was likely declining $\left(\lambda_{\text {Pradel }}=0.95 \pm 0.03 \mathrm{SE} ; \lambda_{\text {secr }}=0.98 \pm 0.02 \mathrm{SE}\right)$. Estimates of apparent survival and apparent recruitment indicated that lower recruitment was the dominant factor limiting population growth in the smaller population. Factors limiting reproductive rates and population density could include poor habitat quality, particularly the abundance of high-energy foods, genetic Allee effects due to a long period of population isolation, or demographic effects affecting infanticide rates. The cessation of hunting was insufficient to promote population recovery for the low density, isolated population. Our research highlights the importance of considering mortality thresholds in addition to small population effects and habitat quality when recovering large carnivore populations.
\end{abstract}

\section{Introduction}

Over half of the world's terrestrial large carnivore populations are declining because of habitat fragmentation, habitat loss, and humancaused mortality (HCM) (calculated for species $>50 \mathrm{~kg}$ from IUCN, 2015; Myhrvold et al., 2015). Large carnivores are often killed by humans because they pose real or perceived threats to personal safety and property such as livestock. In addition, some large carnivore species are also hunted for sport, animal parts (Weber and Rabinowitz, 1996), or because they are in competition with humans for prey (e.g., Riley et al., 2004). The result is a common geographic pattern of extinction that begins with the contraction of species distribution into peninsulas and islands of occupancy which are then sequentially extirpated over time (Henschel et al., 2014; Kenney et al., 2014; Proctor et al., 2012; van Oort et al., 2011). Extirpation is accelerated because, in addition to mechanisms initiating the decline, isolated populations face synergistic effects of population smallness such as vulnerability to stochastic change as well as genetic and demographic Allee effects (Berec et al., 2007; Brook et al., 2008; Caughley, 1994).

The distribution and population size of brown and grizzly bears (Ursus arctos) have declined globally over the past two centuries as a result of habitat loss, habitat fragmentation, and persecution by humans (Mattson and Merrill, 2002; McLellan et al., 2016). For example, grizzly bears in North America have been extirpated from approximately $42 \%$ of their historical range (calculated from IUCN spatial information; McLellan et al., 2016). Extirpation has primarily occurred in the lower 48 states of the USA and the prairies, boreal forest and taiga of central and northeastern Canada (Fig. 1a). The northern portion of their current North American distribution is expansive but towards their southwestern extent, grizzly bears are now restricted to two narrow peninsulas of occupancy; one along the interior Rocky and Columbia mountain ranges, and the other along the Coastal Mountain ranges (Fig. 1a). Both peninsulas of occupancy end in isolated populations of varying sizes (Kendall et al., 2009; McLellan, 2015; Proctor et al., 2012)

\footnotetext{
* Corresponding author.

E-mail address: mclellan.wildlife.research@gmail.com (M.L. McLellan).
} 

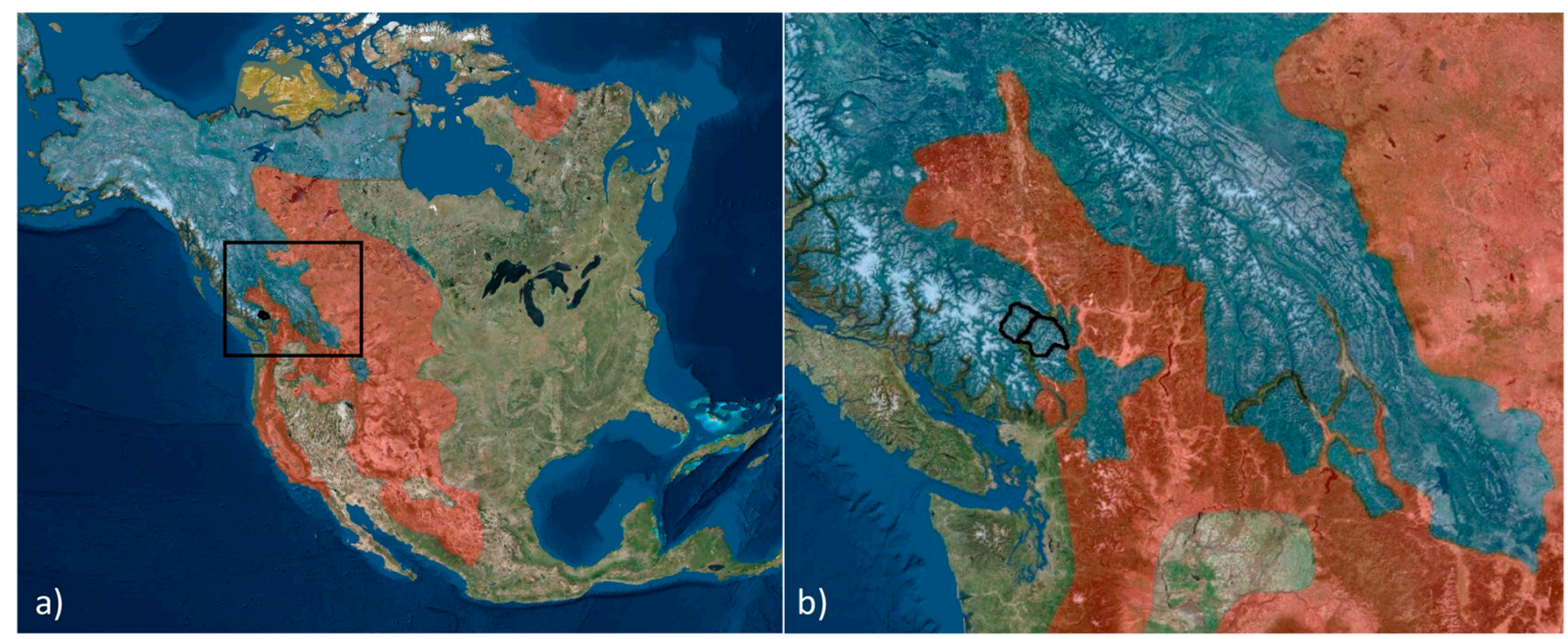

Fig. 1. a) Extant (blue), vagrant (ochre) and extinct (red) distribution of grizzly bears in central western North America (McLellan et al., 2016). b) Inset panel showing the distribution of grizzly bears in western North America and the two peninsulas of occupancy (blue). The location of the study area boundaries is outlined in black. The line dividing the study area marks the genetic population fracture between the McGillvary Mountains (MM) part of the South Chilcotin and northern part of the Stein-Nahatlatch (NSN) grizzly bear populations in southwest British Columbia, Canada. There is relatively low population density of grizzly bears south of the NSN study area. (For interpretation of the references to color in this figure legend, the reader is referred to the web version of this article.)

fragmented by natural landscape features and human settlements.

There have been numerous grizzly bear research projects along the interior peninsula of North American occupancy that identified HCM as the primary limiting factor (Garshelis et al., 2005; Kendall et al., 2009; Mace et al., 2012; McLellan, 2015; Schwartz et al., 2006). As with many other large carnivores, HCM for grizzly bears includes legal hunting, defence of human life or property, road and rail kills, and poaching. Reducing HCM has been the dominant approach for recovering grizzly bears and in some areas, including the Yellowstone and Northern Continental Divide ecosystems in the USA and northern Sweden, this strategy has been highly successful (Kindberg et al., 2011; Mace et al., 2012; Schwartz et al., 2006). Populations limited by HCM have relatively high adult mortality rates and will often have high recruitment rates because populations are perpetually below carrying capacity (McLellan, 2015; Miller et al., 2003). In such conditions reducing HCM is expected to increase adult survival rates allowing populations to grow towards carrying capacity.

In contrast to the interior populations of North America, there has been very little research along the coastal peninsula of grizzly bear occupancy. The limited available information suggests that the status of at least some populations appears extremely tenuous (Apps et al., 2014; Romain-Bondi et al., 2004). Specifically, the provincial government of British Columbia, Canada, considered the five most southerly populations to be Threatened (Grizzly Bears - Environmental Reporting BC, 2012) and in 2000, declared a moratorium on grizzly bear hunting there due to suspected low population density and probable decline. Five years after the hunt ended, a DNA-based population study that included 4 of these Threatened populations, identified major geographic and genetic fractures as well as large differences in grizzly bear density among populations (Apps et al., 2014). Based on genetic evidence, this study also suggested reconnection and possibly population expansion in some areas, but actual trends or demographic mechanisms were not addressed.

Our goal was to quantify population trends and the relative contribution of survival and reproduction to population change in portions of two adjacent but mostly disjunct portions of Threatened grizzly bear populations at the southwestern extent of their range; the McGillvary Mountain (MM) and the North Stein-Nahatlatch (NSN) populations (Fig. 1b). As a result of the hunting moratorium both populations experienced a decline in known HCM; between 1978 and 1999 the known
HCM has declined from 0.72 bears/year in the MM and 0.50 bears/year in the NSN to 0.12 bears/year in both populations (Grizzly Bears Environmental Reporting BC, 2012). We wanted to establish whether populations were recovering following the cessation of the legal hunt and, if not, whether adult mortality or low recruitment were limiting growth.

Based on what is known of grizzly bear ecology and conservation from studies in the interior mountains (Garshelis et al., 2005; Mace et al., 2012; McLellan, 2015; McLellan et al., 1999), we derived three alternative hypotheses and corresponding predictions: (1) The grizzly bear populations were limited by HCM in the past, but due to the reduction in HCM following the hunting moratorium, they are now recovering. If this hypothesis is supported, we predict high population growth rates resulting from high recruitment and high adult survival rates. (2) The grizzly bear populations remain limited by high HCM, restricting population recovery. If this alternative hypothesis is supported, we predict relatively low adult survival but high recruitment rates because populations are being held below carrying capacity. (3) The grizzly bear population growth is not solely being limited by HCM but by other effects such as poor habitat quality. If this hypothesis is supported, we predict moderate to high adult survival because few adult bears are being killed by HCM, but low recruitment rates.

To measure the support for these hypotheses, we used non-invasive DNA sampling of hair traps (Woods et al., 1999) and rub-trees (Kendall et al., 2009) to estimate population densities, trends and the demographic components of population change. We used spatial capturerecapture (SCR) techniques to estimate population-specific density and trends (Borchers and Efford, 2008; Efford, 2004). We then used a robust design Pradel capture-recapture model for open populations to estimate apparent survival $(\varphi)$ and apparent recruitment $(f)$, and identify their relative contributions to the realized population growth $(\lambda)$ for each population (Nichols et al., 2000; Pradel, 1996).

\section{Methods}

\subsection{Study area}

Our study area spanned $4640 \mathrm{~km}^{2}$ in portions of the MM and NSN populations $\left(50.5^{\circ} \mathrm{N}, 122.5^{\circ} \mathrm{W}\right.$; Fig. $\left.1 \mathrm{~b}\right)$. Both populations are in the eastern portion of the Coast Mountain Range of British Columbia, with elevations in the study area ranging from $240 \mathrm{~m}$ to $2783 \mathrm{~m}$. Air masses 
moving eastward from the Pacific Ocean dominate the climate and result in temperate rain forests on the west side of the mountain range, but conditions become increasingly dry towards the rain shadow in the eastern mountains. See McLellan and McLellan (2015) for a detailed description.

The populations are divided by several small communities along a minor highway and 2 lakes that together are approximately $45 \mathrm{~km}$ long and $1.5 \mathrm{~km}$ wide. The NSN population is also bisected by a mountain highway without human-settlement and collared male bears cross it regularly. The southern boundary of the study area is the Stein River located in the center of a large $\left(1300 \mathrm{~km}^{2}\right)$, un-roaded protected area. The northern boundary of the MM study area is Carpenter Reservoir and several small human settlements. The genetic distance fixation index for these populations indicated that they were genetically separate with little interbreeding (Apps et al., 2014).

\subsection{DNA capture-recapture}

We used DNA capture-recapture data from two different studies. The first occurred in 2005 and 2006 when Apps et al. (2014) estimated grizzly bear population density across the southern Coast Mountain ranges. The second study occurred annually from 2010 to 2017 and spanned the MM and NSN portion defined as our study area (Fig. 1b). For both studies, hair traps consisted of one barbed wire strand tightly strung between trees, approximately $50 \mathrm{~cm}$ above the ground, forming a small corral around a pile of debris and scent lure (Woods et al., 1999). We visited traps every 2 to 5 weeks starting in late June to remove hair and re-bait. Each visit constituted a capture occasion, and for each occasion, traps within a population were visited within 3 days of one another. The number of occasions each year varied from 3 to 6 . Wildlife Genetics International (Nelson, British Columbia) screened samples, extracted DNA, carried out genotyping to 22 microsatellite loci, and identified individuals following established techniques (Paetkau, 2003). The extent of the trap arrays remained nearly identical among years, though specific trap locations were often moved (Appendix 1). The annual minimum convex polygon (MCP) surrounding the trap arrays was $587 \mathrm{~km}^{2}$ $\left(\mathrm{SD}=41 \mathrm{~km}^{2}\right)$ in the NSN and $646 \mathrm{~km}^{2}\left(\mathrm{SD}=80 \mathrm{~km}^{2}\right)$ in the MM. The average seasonal MCP home range for GPS collared females in these populations is $146 \mathrm{~km}^{2}(\mathrm{~N}=24$; unpublished data) therefore the trap array was large enough to encompass home ranges of multiple females, with multiple traps within each home-range.

For the first study (2005-2006), one trap was placed in each $10 \times 10 \mathrm{~km}$ cell resulting in 13 traps per population amounting to approximately 1 trap in every major drainage within the study area. For the second study (2010-2017), the number of traps used in each population varied from 12 to 43 among years. At least 1 , and often 2 or 3 hair-traps were set within each drainage, depending on the size of the drainage (Appendix 1).

For the second study, known rub trees were used in addition to hair traps to collect hair samples. One strand of barbed wire was attached to the rub tree and then revisited at the same occasion schedule as the hair traps. Because new rub trees were discovered, and old ones were sometimes removed by logging, the number of rub trees varied across years between 0 and 19 trees for the MM and 0 and 22 for the NSN. Trap-type and differing capture efforts among years (number of traps) and occasions (length) were included as covariates in the population models (see Sections 2.3 and 2.4).

\subsection{Changes in population density}

We estimated changes in population density $(\widehat{D})$ for the MM and the NSN populations by fitting SCR models by maximizing the full likelihood (Borchers and Efford, 2008) using secr package v.3.1.0; (Efford, 2018) in program R. We treated each population separately and intraannual capture-recapture occasions were nested within independent annual sessions. Grizzly bears have offspring during winter and therefore populations were assumed to be closed across occasions of the same year (no births, deaths, immigration or emigration) and open between consecutive years (sessions). Both hair traps and rub trees allow capture of multiple individuals at a detector on one occasion and an animal may be caught in multiple traps on one occasion. In secr, traps with these characteristics are defined as "proximity" detectors and the capture probabilities are estimated accordingly (Efford et al., 2013). We defined the state space of density models (i.e., the area from which bears could potentially be captured) using a buffer around the hair trap/rub tree polygon of 3 times the root pooled spatial variance of each individual's location dispersion (Efford, 2004). We limited the resulting state-space at known population fractures using a spatial mask. SCR models estimate individual and trap-specific detection probabilities as a declining function of the distance between a trap and the individual's estimated activity center. We used a half normal detection function governed by two parameters: the baseline detection probability $g 0$, describing detection probability at the individual's activity center, and the scale parameter $\sigma$, which governs how quickly detection probability declines with distance and is related to how far animals move (e.g.: Borchers and Efford, 2008; Efford, 2004).

We used a three-step model comparison approach with differing detection and density covariates to estimate density trends in each population while minimizing the number of models compared. The objective of the first two steps was to incorporate potential variability in detection probability parameters $g 0$ and $\sigma$ due to individual heterogeneity and sampling design. In the first step, we compared a model where traps were either used or unused for each occasion (binary), with a model where closed traps were classified as unused 0 but trapping effort for open traps was equivalent to the number of days in that occasion so that $g 0$ will vary linearly (on a link scale) with the time the trap was open (Efford et al., 2013). Density could vary among years $(D \sim$ session) while $\sigma$ was assumed to be constant across years $(\sigma \sim 1)$. We used Akaike's information criterion for small samples (AICc) to compare models (Burnham and Anderson, 2002). Models within 2 $\triangle$ AICc units of the top were incorporated into the model structure for the subsequent model comparison steps.

In the second step, we selected the best model for estimating detection probability parameters ( $g 0$ and $\sigma$ ). We used the usage structure identified in step one and again allowed density to vary among years while we compared models that included covariates thought to influence the baseline detection probability $g 0$ : Trap-type (type), occasion timing (time), sex, and the interactions among them ( $\mathrm{O} 0 \sim$ type $*$ sex; type $*$ time; sex $*$ time). Male grizzly bears usually have much larger home ranges than females resulting in a higher capture probability further from their activity centers; therefore we included models with sex as a covariate for $\sigma$ in our model selection process.

In the final step, we used the top detection model from step 2 to estimate the change in density across years $(D \sim$ year) by using sessionnumber (in years) as a predictor. This fitted trend is linear on the link scale and corresponds to exponential growth or decline. Density is estimated as a function of year on the log-link scale, therefore the estimated $\beta$ parameter is equivalent to $r$ in the exponential growth curve $D_{t}=D_{t-1} e^{r}$ where $D_{t}$ is density at time $t$ and $D_{t-1}$ is density at time $t-1$ year. The finite rate of increase, or Pradel's lambda, is then $\lambda=\exp (r)$. The density trend model was compared to a model with density held constant across years $(D \sim 1)$ and a model where each session had unique densities without a trend ( $D \sim$ session). If competing models were $<2 \Delta$ AICc units of the best model, we used AIC weights $\left(\omega_{\mathrm{i}}\right)$ for each candidate model to obtain model-averaged mean and variance parameter estimates for density $(\widehat{D})$ and capture probability parameters $g 0$ and $\sigma$ (Burnham and Anderson, 2002).

\subsection{Apparent survival and recruitment}

To identify the components of population change, we used the same data described in Sections 2.2 and 2.3 in a Pradel robust design (PRD) 
framework. This approach allows estimation of demographic parameters in open populations (Nichols and Hines, 2002; Pradel, 1996) while using the Huggins conditional likelihood approach for estimating detection probabilities $(p)$ and recapture probabilities $(c)$ in closed populations (Huggins, 1991). We parameterized the PRD model to estimate apparent survival $(\varphi)$ and apparent recruitment $(f)$, capture probability $(p)$ and derive realized population growth $(\lambda)$ for both the NSN and MM populations. Apparent survival $(\varphi)$ is the probability that an individual remains in the population and does not die or emigrate, and apparent recruitment $(f)$ is the probability of an individual entering the population through birth or immigration. These parameters are estimated between years and can be summed for each interval to produce the realized population growth $(\lambda)$. Analyses were conducted using the RMark package (Laake and Rexstad, 2008; White and Burnham, 1999) in program R v.3.4.0 (R Core Development Team, 2017).

Like the spatial capture-recapture modelling in Section 2.3, we used a three-step model selection approach. In the first step, we allowed apparent survival $(\varphi)$ and apparent recruitment $(f)$ to vary by sex and population in order to explore the effect of effort on detection probability $p$. Detection probability was constrained so that initial capture $(p)$ and recapture probabilities $(c)$ were the same. Effort was defined as either the number of traps open per occasion or, alternatively, the number of total trap nights for each occasion (number of traps $\mathrm{x}$ occasion length). The model with the lowest AICc score was used to define effort in the subsequent steps.

In the second step, covariates for capture probability $(p)$ included trap-type, sex, population, occasion specific time, effort, as determined from step one, and interactions between sex and trap-type, and time and trap-type. Trap-type is known to influence capture probability (Lamb et al., 2016); therefore captures at hair traps and rub trees were included as separate sequential sessions (e.g., Boulanger et al., 2008).

In the final step, we used the model structure for capture probability determined in the previous steps and modelled variation in demographic rates. We hypothesized that both apparent survival and apparent recruitment could vary between populations and sexes. We compared all combinations of sex and populations, with models keeping these rates constant, resulting in 16 models. We used the same model averaging techniques described in Section 2.3 to obtain estimates of apparent survival and recruitment and their variances (Burnham and Anderson, 2002). We derived estimates for population growth $(\lambda)$ from model-averaged estimates of apparent survival $(\varphi)$ and recruitment $(f)$.

Population-specific estimates for apparent survival $(\varphi)$ and recruitment $(f)$ were obtained by comparing models where one or both parameters could vary by population or be constant between populations. We used AICc weights from the four competing models to obtain model-averaged estimates of apparent survival $(\varphi)$ apparent recruitment $(f)$ and derived lambda $(\lambda)$ in each population.

\section{Results}

Between 2005 and 2017, 78 (37 F, 41 M) grizzly bears were detected 479 times in the MM and 26 individuals $(12 \mathrm{~F}, 14 \mathrm{M})$ were detected 176 times in the NSN (Table 1). Three male bears moved between populations: two from the NSN to the MM and one from the MM to the NSN. These individuals were handled as independent in each population. One additional adult male was known by his genetic structure to have NSN origin but was only captured in the MM. We did not detect any female movement between populations. In the last 4 years of monitoring, we marked an average of 9 new bears/year in the MM and but only 0.5 new bears/year in the similarly sized trap array over the NSN (Table 1).

\subsection{Spatial mark-recapture density trends}

Grizzly bear population density and trend differed between the two populations. The top model for the MM population indicated that density was increasing $(D \sim$ year $)$ with a growth rate of $\lambda_{\text {secr }}$ $=1.01 \pm 4.6 \times 10^{-5} \mathrm{SE}$ from 18.7 bears $/ 1000 \mathrm{~km}^{2}$ in 2006 to 21.5 bears $/ 1000 \mathrm{~km}^{2}$ in 2016 (Table 2; Fig. 2). In the NSN population, the top two models for density were a model allowing density to change across years $(D \sim$ year $)$ at a rate of $\lambda_{\text {secr }}=0.97 \pm 7.3 \times 10^{-5} \mathrm{SE}$ and the null model, where density was constant across years (Table 2). Model-averaged results for density estimation and trend for the NSN population indicated that the population was either stable or slowly declining $\lambda_{\text {secr }}=0.98 \pm 0.02 \mathrm{SE}$ from 7.7 bears $/ 1000 \mathrm{~km}^{2}$ in 2005 to 6.3 bears/ $1000 \mathrm{~km}^{2}$ in 2017 (Fig. 2).

Top models for detection probability parameters, $g 0$ and $\sigma$, were the same for both populations. The best model for $g 0$ included sex, traptype, and sex-trap-type interactions as covariates and the best model for $\sigma$ included sex as a covariate (Appendix 2). Effort, defined as a binary variable indicating whether a trap was used or unused, performed better than models using the number of days to indicate usage (Appendix 2).

Mean baseline detection probabilities $g 0$, were similar for females in both populations but higher for males in the MM than in the NSN population (Table 3). Trap-type had little effect on the detection probability of males, but females were 6.4 and 3.7 times more likely to be detected at hair traps than rub trees in the NSN and MM population respectively (Table 3). Males had larger $\sigma$ than females, and while $\sigma$ for females was similar for both populations, $\sigma$ for males was larger in the NSN (Table 3).

\subsection{Demographic components of trends}

The top three models for estimating apparent survival $(\varphi)$ and apparent recruitment $(f)$ had similar support and included sex or sex and population as covariates (Table 4; Appendix 3). Model-averaged estimates of apparent survival $(\varphi)$ were lower for males than females in both populations, and slightly lower for both males and females in the NSN than the MM (Fig. 3a, Appendix 4). Apparent recruitment ( $f$ ) was higher for males than females in both populations and was lower for both sexes in the NSN than the MM (Fig. 3c). Model-averaged estimates of population growth by sex were $\lambda_{\text {Female }}=1.03 \pm 0.02 \mathrm{SE}$ and $\lambda_{\text {Male }}=1.01 \pm 0.02 \mathrm{SE}$ in the MM and $\lambda_{\text {Female }}=0.98 \pm 0.03 \mathrm{SE}$ and $\lambda_{\text {Male }}=0.92 \pm 0.04$ SE in the NSN (Fig. 3e).

When parameters were constrained to obtain estimates for each population independent of sex, apparent survival and apparent recruitment were higher in the MM than the NSN (Fig. 3b and c). Derived population growth $(\lambda)$ showed divergent population trends with the MM population growing $(\lambda=1.02 \pm 0.02 \mathrm{SE})$ and the NSN population declining $(\lambda=0.95 \pm 0.03 \mathrm{SE})$.

Top models for detection probability $(p)$ had the same model structure as the spatial mark-recapture analysis. The top model included sex, trap-type, sex $*$ trap-type interaction, and effort as covariates for $p$, where effort was the number of traps used each occasion (Appendix 2).

\section{Discussion}

We identified different population densities and divergent population trends in 2 threatened grizzly bear populations in British Columbia monitored from 5 to 17 years after the end of legal hunting. The MM population was growing and had 3.4 times the population density of the adjacent, and likely declining, NSN population (Fig. 2). Both spatial and non-spatial estimates of population growth showed a similar trend, though non-spatial estimates were more divergent between populations with a more precipitous decline for the NSN population. Estimation of demographic parameters revealed that both apparent survival and recruitment were lower in the NSN, though the difference in apparent recruitment between the populations was consistently greater than that of apparent survival (Fig. 3). The differences in the demographic components of population change between populations can be used to 
Table 1

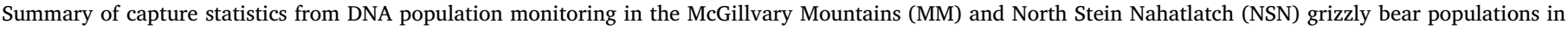

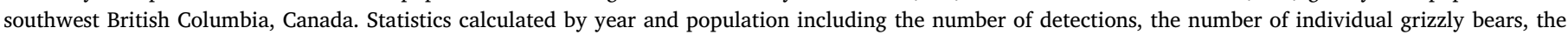

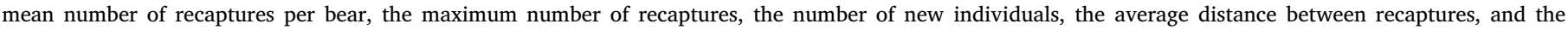
maximum distance between recaptures.

\begin{tabular}{|c|c|c|c|c|c|c|c|c|}
\hline \multirow[t]{2}{*}{ Pop } & \multirow[t]{2}{*}{ Year } & \multirow[t]{2}{*}{ Detections } & \multirow[t]{2}{*}{ No. individuals } & \multirow[t]{2}{*}{ Recaptures } & \multirow[t]{2}{*}{ Max. recaptures } & \multirow[t]{2}{*}{ New individuals } & \multicolumn{2}{|c|}{ Distance between recaptures $(\mathrm{km})$} \\
\hline & & & & & & & Mean & Max \\
\hline \multirow[t]{7}{*}{ McGillvary Mountains } & 2006 & 53 & 24 & 2.21 & 8 & 24 & 4.47 & 20.19 \\
\hline & 2010 & 31 & 16 & 1.92 & 7 & 8 & 7.43 & 21.03 \\
\hline & 2011 & 68 & 26 & 2.62 & 10 & 10 & 6.46 & 25.02 \\
\hline & 2012 & 70 & 31 & 2.23 & 8 & 8 & 6.83 & 24.72 \\
\hline & 2013 & 76 & 25 & 3.04 & 11 & 8 & 5.81 & 16.81 \\
\hline & 2014 & 69 & 33 & 2.09 & 8 & 11 & 6.40 & 43.10 \\
\hline & 2016 & 112 & 39 & 2.87 & 11 & 9 & 6.63 & 34.26 \\
\hline \multirow[t]{8}{*}{ North Stein-Nahatlatch } & 2005 & 31 & 13 & 2.2 & 7 & 13 & 9.93 & 21.07 \\
\hline & 2010 & 13 & 9 & 1.44 & 3 & 6 & 12.84 & 26.81 \\
\hline & 2011 & 15 & 9 & 1.67 & 4 & 1 & 11.54 & 20.36 \\
\hline & 2012 & 28 & 13 & 2.15 & 6 & 4 & 5.63 & 12.75 \\
\hline & 2013 & 26 & 8 & 3.25 & 6 & 0 & 6.48 & 18.88 \\
\hline & 2014 & 25 & 8 & 3.13 & 8 & 1 & 9.05 & 32.67 \\
\hline & 2015 & 24 & 8 & 3 & 8 & 1 & 9.33 & 28.36 \\
\hline & 2017 & 14 & 6 & 2.5 & 4 & 0 & 3.90 & 16.02 \\
\hline
\end{tabular}

Table 2

Spatial capture-recapture model selection for estimating trend in population density for the McGillvary Mountains (MM) and North Stein Nahatlatch (NSN) grizzly bear populations in southwest British Columbia, Canada. The null model $(D \sim 1)$, indicating no change in density between years, was compared to models where density was different among years ( $D \sim$ session) and where density was changing as a linear function of time ( $D \sim$ year) indicating population growth or decline. We included trap-type and sex as covariates for the probability of detection at the activity center of an individual $(\mathrm{g} O)$ and sex as a covariate for the scale parameter of the detection function $(\sigma)$. See Appendix 2 for model selection results for detection parameters.

\begin{tabular}{lllll}
\hline Population & Density Model & $\mathrm{K}^{\mathrm{a}}$ & $\Delta \mathrm{AICc}^{\mathrm{b}}$ & $\omega_{\mathrm{i}}^{\mathrm{c}}$ \\
\hline MM & $D(\sim$ year $)$ & 9 & 0.00 & 1.00 \\
& $D(\sim$ session $)$ & 14 & 10.18 & 0.00 \\
& $D(\sim 1)$ & 8 & 10.34 & 0.00 \\
\hline \multirow{2}{*}{ NSN } & $D(\sim$ year $)$ & 9 & 0.00 & 0.52 \\
& $D(\sim 1)$ & 8 & 0.16 & 0.48 \\
& $D(\sim$ session $)$ & 15 & 10.49 & 0.00 \\
\hline
\end{tabular}

${ }^{\text {a }}$ Number of model parameters.

b Difference between AICc of the model and the AICc of the highest ranked model.

c Model weight.

identify possible mechanisms of change as is necessary to facilitate recovery.

The increasing population trend in the MM population following the reduction of reported HCM is consistent with findings from the interior mountains of North America and Europe where populations have been recovering following a decline in HCM (Chapron et al., 2014; Mace et al., 2012; Schwartz et al., 2006). Although HCM, for reasons other than hunting, may eventually limit the MM population, the reduction of HCM following the end of hunting has been sufficient for the population to begin recovering. In contrast, despite the reduction in known HCM, the small, isolated NSN population is not growing, and the probable decline is mostly the result of low recruitment. Low recruitment in conjunction with slightly lower adult survival, is consistent with the hypothesis that other major limiting factors are affecting the NSN population, and reduction of HCM has been insufficient to recover this population.

Identifying the contribution of permanent migration to apparent survival and apparent recruitment increases our understanding of the mechanisms driving population change. Although we did not measure these movements directly, permanent migration rates and dispersal distances from natal home ranges, including differences between sexes, have been well documented for grizzly bears (Graves et al., 2014; McLellan and Hovey, 2001; Proctor et al., 2004). Using this information and the genetic ancestry information from bears in the study populations, we can hypothesize the likely contribution of migration to apparent survival and recruitment. Female grizzlies are usually philopatric and remain in their natal population, while male grizzlies tend to disperse farther and have larger home ranges (McLellan and Hovey, 2001; Proctor et al., 2004). We observed 3 events of permanent dispersal when 2 marked males emigrated from the NSN to the MM and 1 from the MM to the NSN. We did not detect any inter-population dispersal of females, nor did we capture any females with a genetic profile suggesting ancestry from a different population. Studies on captive brown bears show that birth rates are similar for both sexes (Tumanov, 1995), therefore, if females are likely to remain in their natal home ranges, and males and females are born with equal probability, then it is likely that female apparent recruitment rate is near the actual recruitment rate of grizzlies at the age when they are more commonly caught in hair traps.

Several mechanisms could explain why recruitment rates were lower in the NSN than the MM. In other populations, habitat quality and, in particular, the abundance of high-energy foods has been shown to limit reproductive rates and population density (McLellan, 2015; Schwartz et al., 2006). Perhaps poorer habitat quality in the NSN resulted in smaller litters, increased inter-birth intervals, delayed age of primiparity or high cub mortality. Lower reproductive output could also be due to a long period of population isolation leading to a genetic Allee effect (Keller and Waller, 2002; Laikre et al., 1996). The observed heterozygosity was $\mathrm{H}_{\mathrm{o}}=0.61$ for the MM and $\mathrm{H}_{\mathrm{o}}=0.51$ for the NSN (unpublished data); though both are below the average for North American populations $\left(\mathrm{H}_{\mathrm{o}}=0.65\right.$; Cronin and MacNeil, 2012) heterozygosity is higher than that observed for other threatened and isolated brown bear populations (e.g., Gobi desert, $\mathrm{H}_{\mathrm{o}}=0.29$, Tumendemberel et al., 2015; Pyrenees prior to augmentation, $\mathrm{H}_{\mathrm{o}}=0.25$, Taberlet et al., 1997). Finally, low reproductive success could also result from sexually selected infanticide exacerbated by small population demographic effects such as skewed sex ratio or years with no reproductively available females (Wielgus and Bunnell, 1994).

In both populations we studied, females had higher apparent survival than males, and survival was slightly higher in the MM than the NSN (Fig. 3); though standard errors of sex-specific estimates between populations overlapped. Male dispersal distances are larger than those of females (McLellan and Hovey, 2001; Proctor et al., 2004) and loss 


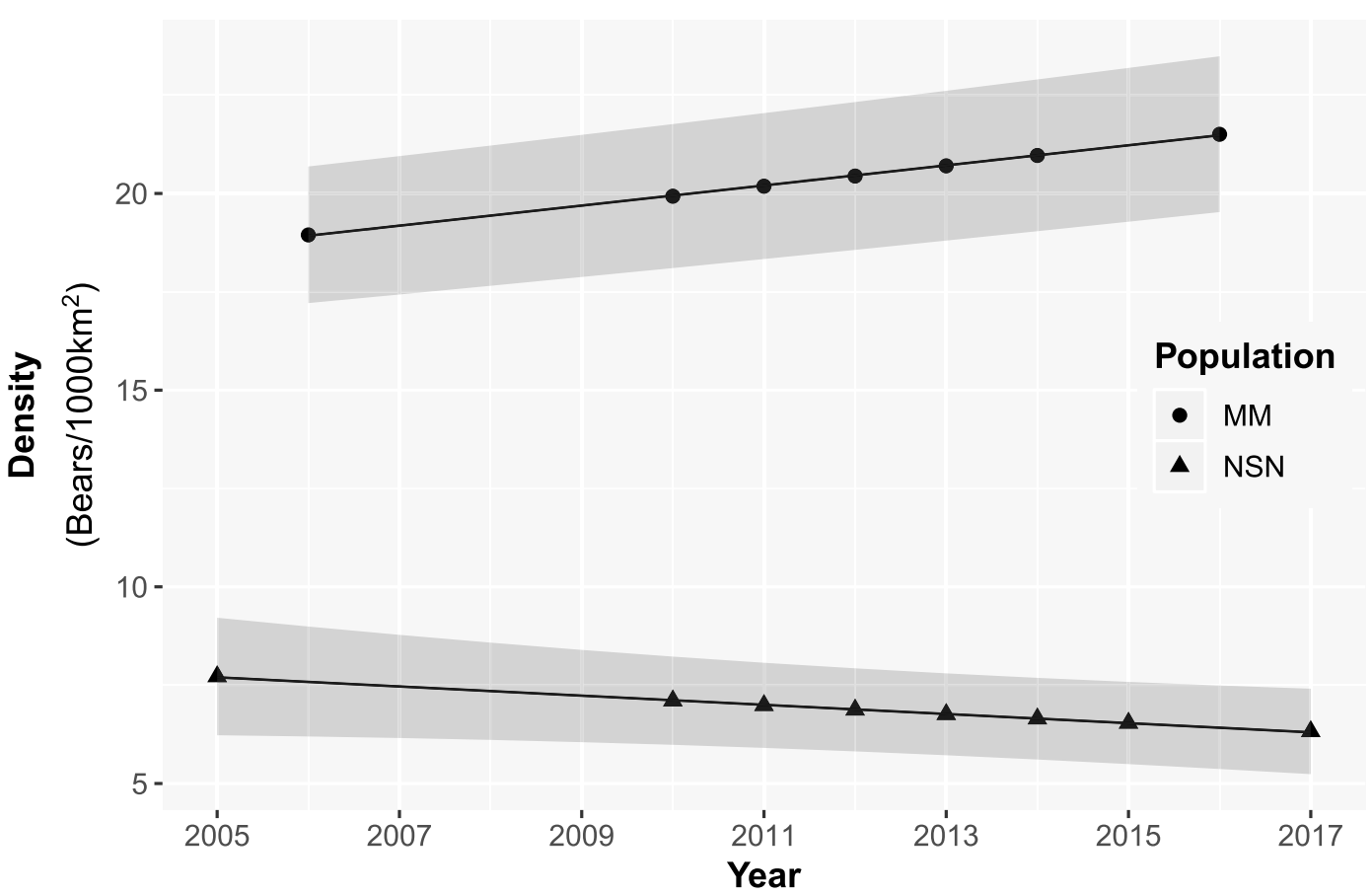

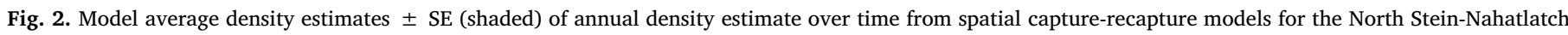
(NSN) and McGillvary Mountain (MM) portions of the South Chilcotin grizzly bear populations, British Columbia, Canada.

due to emigration likely contributed to some of the differences in apparent survival between sexes. Mortality rates of male grizzlies, even in un-hunted populations, are often higher than for other cohorts (McLellan et al., 1999) and therefore would also contribute to reduced apparent survival for males. Apparent survival rates were higher in the MM and NSN populations than estimates from Banff National Park, Alberta, another un-hunted population sampled using similar methods. There, a high incidence of road and train kill is suspected to have decreased grizzly bear survival (Whittington and Sawaya, 2015). The slightly lower apparent survival rates of grizzlies in the NSN than in the MM suggests that factors other than HCM may be affecting survival, however, identifying differences in causes of mortality would be required to test this hypothesis.

Although increasing, the density of grizzly bears in the MM (21.5 bears $/ 1000 \mathrm{~km}^{2}$ ) is currently similar to the average (22.3 bears/ $1000 \mathrm{~km}^{2}$ ) of 75 populations in North America that have little or no salmon in their diets (compiled by Mowat et al., 2013), but slightly lower than the average for British Columbia (27.4 bears $/ 1000 \mathrm{~km}^{2}$, $\mathrm{n}=28$ ). In contrast, the density of the NSN population (6.3 bears/ $1000 \mathrm{~km}^{2}$ ) is much lower than the average population density of areas with little or no salmon. Although lower bear densities have been recorded in parts of Alberta and the USA, only one of the 28 populations inventoried in British Columbia had a lower density estimate. Densities
Table 4

Pradel robust design models to estimate apparent survival $(\varphi)$ and apparent recruitment $(f)$, for both the McGillvary Mountains (MM) part of the South Chilcotin and North Stein (NSN) part of the Stein-Nahatlatch grizzly bear populations in southwest British Columbia, Canada. Models fit using common detection probability $(p)$ estimated in a prior analysis $p(\sim$ sex + type + effort + (sex $*$ type). Effort refers to the number of traps per occasion and type refers to whether the trap was a hair trap or rub tree.

\begin{tabular}{llccc}
\hline Model & & $\mathrm{K}^{\mathrm{a}}$ & $\Delta \mathrm{AICc}^{\mathrm{b}}$ & $\omega_{\mathrm{i}}{ }^{\mathrm{c}}$ \\
\hline$\varphi(\sim$ sex $)$ & $f(\sim$ sex + pop $)$ & 10 & 0.00 & 0.31 \\
$\varphi(\sim$ sex + pop $)$ & $f(\sim$ sex $)$ & 10 & 1.09 & 0.18 \\
$\varphi(\sim$ sex + pop $)$ & $f(\sim$ sex + pop $)$ & 11 & 1.38 & 0.16 \\
$\varphi(\sim$ sex $)$ & $f(\sim$ pop $)$ & 9 & 2.68 & 0.08 \\
$\varphi(\sim$ sex $)$ & $f(\sim$ sex $)$ & 9 & 2.70 & 0.08 \\
$\varphi(\sim$ sex + pop $)$ & $f(\sim 1)$ & 9 & 3.55 & 0.05 \\
$\varphi(\sim$ sex + pop $)$ & $f(\sim$ pop $)$ & 10 & 3.92 & 0.04 \\
\hline
\end{tabular}

${ }^{\text {a }}$ Number of model parameters.

b Difference between AICc of the model and the AICc of the highest ranked model.

${ }^{\mathrm{c}}$ Model weight.

in the NSN are also lower than most small brown bear populations in Europe despite the latter having relatively high surrounding human density and modified habitats (e.g., 38 bears $/ 1000 \mathrm{~km}^{2}$ in the Italian

Table 3

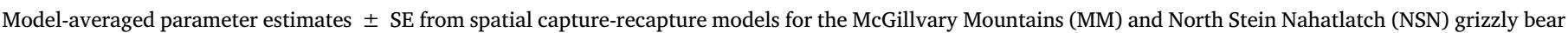

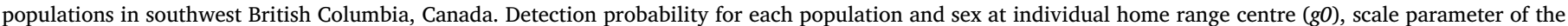
half normal detection function $(\sigma)$ in $\mathrm{km}$. See Fig. 2 and Appendix 2 for model structure.

\begin{tabular}{|c|c|c|c|c|c|c|}
\hline \multirow[t]{2}{*}{ Population } & \multirow[t]{2}{*}{ Density $^{\mathrm{a}}$} & \multirow[t]{2}{*}{$\lambda$} & \multirow[t]{2}{*}{ Sex } & \multicolumn{2}{|c|}{$g 0$} & \multirow[t]{2}{*}{$\sigma(\mathrm{km})$} \\
\hline & & & & Hair trap & Rub tree & \\
\hline \multirow[t]{2}{*}{ MM } & $21.50 \pm 1.98$ & $1.01 \pm 4.52 \times 10^{-5}$ & $\mathrm{~F}$ & $0.31 \pm 0.03$ & $0.08 \pm 0.02$ & $4.41 \pm 0.27$ \\
\hline & & & M & $0.22 \pm 0.03$ & $0.21 \pm 0.03$ & $7.91 \pm 0.47$ \\
\hline \multirow[t]{2}{*}{ NSN } & $6.32 \pm 1.09$ & $0.98 \pm 0.02$ & $\mathrm{~F}$ & $0.34 \pm 0.06$ & $0.05 \pm 0.02$ & $3.91 \pm 0.38$ \\
\hline & & & M & $0.13 \pm 0.03$ & $0.15 \pm 0.03$ & $11.48 \pm 1.41$ \\
\hline
\end{tabular}

a Density (bears $/ 1000 \mathrm{~km}^{2}$ ) estimate for last year of sampling in each population. 
a)

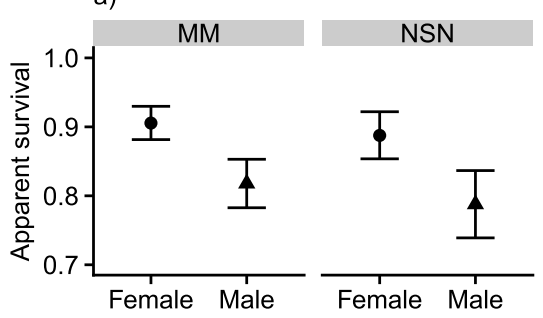

c)

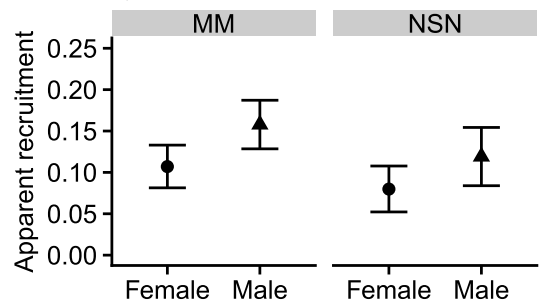

e)

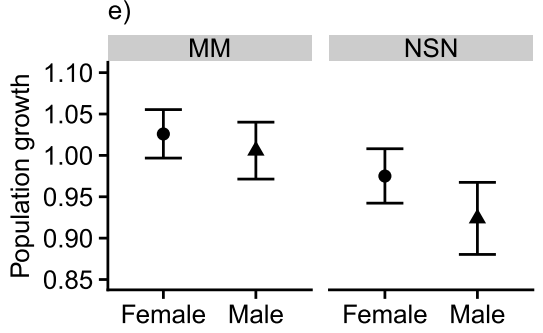

b)

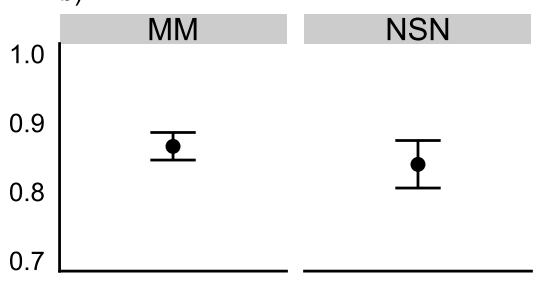

d)

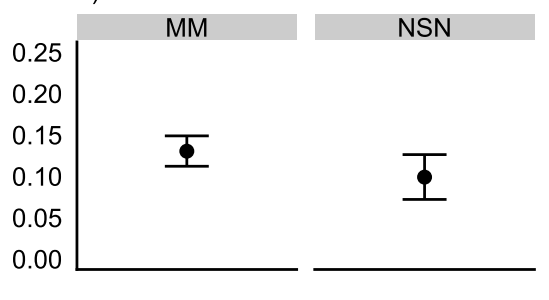

Fig. 3. Pradel robust design model-averaged parameter estimates ( \pm SE) for apparent survival $(\varphi)$, apparent recruitment $(f)$ and population growth $(\lambda)$. Left panels (a,c,e) are modelaveraged estimates where both sex and population were included as covariates. Right panel (b,d,f) model-averaged estimates for each population independent of sex.
Apennines, Ciucci et al., 2015; 21 bears $/ 1000 \mathrm{~km}^{2}$ in the Cantabrian mountains, Martin et al., 2012).

Population growth following the reduction of HCM has been recorded in many North American and European brown bear populations (e.g. Kendall et al., 2009; Kindberg et al., 2011; Mace et al., 2012; Pérez et al., 2014; Schwartz et al., 2006), indicating that reducing HCM may be sufficient to allow population recovery. However, if low-density populations become isolated, other factors may become important. For example, despite reductions in HCM the Pyrenean brown bear population continued to decline from low recruitment until augmentation reversed the trend in the central subpopulation while, in the absence of augmentation, the other subpopulation went functionally extinct (Chapron et al., 2009). Research from other grizzly bear populations suggests that changes in survival as small as a $5 \%$ can result in negative population trends (Eberhardt et al., 1994). In the NSN, the difference between an increasing and stable population could thus be the fate of only one bear (derived population size of study area $N \approx 16$ ) highlighting the importance of stochastic events. Such a stochastic event in this population was that the only bear documented to have moved from the MM population to the NSN population was mistaken for a black bear and shot by a hunter. On the other hand, the only cubs known to survive to maturity have been females. Managing for small populations thus requires additional attention to factors other than HCM.

Acquiring the necessary data from small populations to differentiate among multiple competing, and usually not mutually exclusive, hypotheses of population decline can be difficult because these species often occur at low densities, have long generation times, and low fecundity. Paradoxically, these characteristics predispose populations to extinction in rapidly changing environments (Brook et al., 2008; Caughley, 1994; Purvis et al., 2000). Our research highlights the importance of monitoring populations to understand the efficacy of management and other conservation actions. If a population is small and isolated, removing one major limiting factor, such as legal hunting, may be insufficient to ensure recovery.

\section{Acknowledgements}

Funding was provided by the Habitat Conservation Trust Foundation, the British Columbia Ministry of Forests, Lands, and Natural Resource Operations and the Ministry of Environment. M. McLellan is thankful for a Victoria University of Wellington $\mathrm{PhD}$ scholarship. We thank Steve Rochetta, Bryce Bateman, Jonathan Foulger and Céline Doyon for their contributions to field work and Scott Taylor from Blackcomb Helicopters. Murray Efford kindly provided valuable guidance and suggestions.

\section{Appendix A. Supplementary data}

Supplementary data to this article can be found online at https:// doi.org/10.1016/j.biocon.2019.02.021.

\section{References}

Apps, C., Paetkau, D, Rochetta, S., McLellan, B.N., Hamilton, T., Bateman, B., 2014 Grizzly Bear Population Abundance, Distribution and Connectivity Across British Columbia's Southern Coast Ranges. Project Report Version 2.0.

Berec, L., Angulo, E., Courchamp, F., 2007. Multiple Allee effects and population management. Trends Ecol. Evol. 22, 185-191. https://doi.org/10.1016/j.tree.2006.12. 002 .

Borchers, D.L., Efford, M.G., 2008. Spatially explicit maximum likelihood methods for capture-recapture studies. Biometrics 64, 377-385. https://doi.org/10.1111/j.15410420.2007.00927.x.

Boulanger, J., Kendall, K.C., Stetz, J.B., Roon, D. a, Waits, L.P., Paetkau, D., 2008. Multiple data sources improve DNA-based mark-recapture population estimates of grizzly bears. Ecol. Appl. 18, 577-589. https://doi.org/10.1890/06-1941.1.

Brook, B.W., Sodhi, N.S., Bradshaw, C.J.A., 2008. Synergies among extinction drivers under global change. Trends Ecol. Evol. 23, 453-460. https://doi.org/10.1016/j.tree. 2008.03 .011$.

Burnham, K.P., Anderson, D.R., 2002. Model Selection and Multimodel Inference: A Practical Information-Theoretic Approach, 2nd ed. Springer, New York.

Caughley, G., 1994. Directions in conservation biology. J. Anim. Ecol. 63, 215-244. https://doi.org/10.2307/5542.

Chapron, G., Wielgus, R., Quenette, P.Y., Camarra, J.J., 2009. Diagnosing mechanisms of decline and planning for recovery of an endangered brown bear (Ursus arctos) 
population. PLoS One. https://doi.org/10.1371/journal.pone.0007568.

Chapron, G., Kaczensky, P., Linnell, J.D.C., et al., 2014. Recovery of large carnivores in Europe's modern human-dominated landscapes. Science 346, 1517-1519. https:// doi.org/10.1126/science.1257553.

Ciucci, P., Gervasi, V., Boitani, L., Boulanger, J., Paetkau, D., Prive, R., Tosoni, E., 2015. Estimating abundance of the remnant Apennine brown bear population using multiple noninvasive genetic data sources. J. Mammal. 96, 206-220. https://doi.org/10. 1093/jmammal/gyu029.

Cronin, M.A., MacNeil, M.D., 2012. Genetic relationships of extant brown bears (Ursus arctos) and polar bears (Ursus maritimus). J. Hered. 103, 873-881. https://doi.org/10. 1093/jhered/ess090.

Eberhardt, L.L., Blanchard, B.M., Knight, R.R., 1994. Population trend of the Yellowstone grizzly bear as estimated from reproductive and survival rates. Can. J. Zool. 72 , 360-363. https://doi.org/10.1139/z94-049.

Efford, M., 2004. Density estimation in live-trapping studies. Oikos 106, 598-610. https://doi.org/10.1111/j.0030-1299.2004.13043.x.

Efford, M., 2018. secr 3.1.0 Spatially Explicit Capture-Recapture in R.

Efford, M.G., Borchers, D.L., Mowat, G., 2013. Varying effort in capture-recapture studies. Methods Ecol. Evol. 4, 629-636. https://doi.org/10.1111/2041-210X.12049.

Garshelis, D.L., Gibeau, M.L., Herrero, S., 2005. Grizzly bear demographics in and around Banff National Park and Kananaskis Country, Alberta. J. Wildl. Manag. 69, 227-297.

Graves, T., Chandler, R.B., Royle, J.A., Beier, P., Kendall, K.C., 2014. Estimating landscape resistance to dispersal. Landsc. Ecol. 29, 1201-1211. https://doi.org/10.1007/ s10980-014-0056-5.

Henschel, P., Coad, L., Burton, C., Chataigner, B., Dunn, A., MacDonald, D., Saidu, Y., Hunter, L.T.B., 2014. The lion in West Africa is critically endangered. PLoS One. https://doi.org/10.1371/journal.pone.0083500.

Huggins, R.M., 1991. Some practical aspects of a conditional likelihood approach to capture experiments. Biometrics 47, 725. https://doi.org/10.2307/2532158.

IUCN, 2015. IUCN red list of threatened species. version 2015.4. www.iucnredlist.org.

Keller, L.F., Waller, D.M., 2002. Inbreeding effects in wild populations. Trends Ecol. Evol. 17, 230-241. https://doi.org/10.1016/S0169-5347(02)02489-8.

Kendall, K.C., Stetz, J.B., Boulanger, J., Macleod, A.C., Paetkau, D., White, G.C., 2009 Demography and genetic structure of a recovering brown bear population. J. Wildl. Manag. 73, 3-17. https://doi.org/10.2193/2008-330.

Kenney, J., Allendorf, F.W., Mcdougal, C., Smith, J.L.D., 2014. How much gene flow is needed to avoid inbreeding depression in wild tiger populations? Proc. R. Soc. B 281.

Kindberg, J., Swenson, J.E., Ericsson, G., Bellemain, E., Taberlet, P., 2011. Estimating population size and trends of the Swedish brown bear Ursus arctos population. Wildl. Biol. 17, 114-123. https://doi.org/10.2981/10-100.

Laake, J., Rexstad, E., 2008. RMark - an alternative approach to building linear model in MARK. In: Cooch, E., White, G.C. (Eds.), Program MARK: A Gentle Introduction.

Laikre, L., Andrén, R., Larsson, H.-O., Ryman, N., 1996. Inbreeding depression in brown bear Ursus arctos. Biol. Conserv. 76, 69-72. https://doi.org/10.1016/0006-3207(95) 00084-4.

Lamb, C.T., Walsh, D.A., Mowat, G., 2016. Factors influencing detection of grizzly bears at genetic sampling sites. Ursus 27, 31-44. https://doi.org/10.2192/URSUS-D-1500025.1.

Mace, R.D., Carney, D.W., Chilton-Radandt, T., Courville, S.A., Haroldson, M.A., Harris, R.B., Jonkel, J., McLellan, B., Madel, M., Manley, T.L., Schwartz, C.C., Servheen, C., Stenhouse, G., Waller, J.S., Wenum, E., 2012. Grizzly bear population vital rates and trend in the Northern Continental Divide Ecosystem, Montana. J. Wildl. Manag. 76, 119-128. https://doi.org/10.1002/jwmg.250.

Martin, J., Revilla, E., Quenette, P.Y., Naves, J., Allainé, D., Swenson, J.E., 2012. Brown bear habitat suitability in the Pyrenees: transferability across sites and linking scales to make the most of scarce data. J. Appl. Ecol. 49, 621-631. https://doi.org/10. 1111/j.1365-2664.2012.02139.x.

Mattson, D.J., Merrill, T., 2002. Extirpations of grizzly bears in the contiguous United States, 1850-2000. Conserv. Biol. 16, 1123-1136. https://doi.org/10.1046/j.15231739.2002.00414.x.

McLellan, B.N., 2015. Some mechanisms underlying variation in vital rates of grizzly bears on a multiple use landscape. J. Wildl. Manag. 79, 749-765. https://doi.org/10. 1002/jwmg.896.

McLellan, B.N., Hovey, F.W., 2001. Natal dispersal of grizzly bears. Can. J. Zool. 79, 838-844. https://doi.org/10.1139/cjz-79-5-838.

McLellan, M.L., McLellan, B.N., 2015. Effect of season and high ambient temperature on activity levels and patterns of grizzly bears (Ursus arctos). PLoS One 10, e0117734. https://doi.org/10.1371/journal.pone.0117734.

McLellan, B.N., Hovey, F.W., Mace, R.D., Woods, J.G., Carney, D.W., Gibeau, M.L. Wakkinen, W.L., Kasworm, W.F., 1999. Rates and causes of grizzly bear mortality in the interior mountains of British Columbia, Alberta, Montana, Washington, and Idaho. J. Wildl. Manag. 63, 911-920. https://doi.org/10.2307/3802805.

McLellan, B.N., Proctor, M.F., Huber, D., Michel, S., 2016. The IUCN red list of threatened species 2016: brown bear. https://doi.org/10.2305/IUCN.UK.2016-3.RLTS.
T41688A45.

Miller, S.D., Sellers, R.A., Keay, J.A., 2003. Effects of hunting on brown bear cub survival and litter size in Alaska. Ursus 14, 130-152.

Mowat, G., Heard, D.C., Schwarz, C.J., 2013. Predicting grizzly bear density in western North America. PLoS One 8, e82757. https://doi.org/10.1371/journal.pone. 0082757.

Myhrvold, N.P., Baldridge, E., Chan, B., Sivam, D., Freeman, D.L., Ernest, S.K.M., 2015. An amniote life-history database to perform comparative analyses with birds, mammals, and reptiles. Ecology 96, 3109-000. https://doi.org/10.1890/15-0846R.1.

Nichols, J.D., Hines, J.E., 2002. Approaches for the direct estimation of $\lambda$, and demographic contributions to $\lambda$, using capture-recapture data. J. Appl. Stat. 29, 539-568. https://doi.org/10.1080/02664760120108809.

Nichols, J.D., Hines, J.E., Lebreton, J.-D., Pradel, R., 2000. Estimation of contributions to population growth: a reverse-time capture-recapture approach. Ecology 81, 3362-3376. https://doi.org/10.2307/177500.

Paetkau, D., 2003. An empirical exploration of data quality in DNA-based population inventories. Mol. Ecol. 12, 1375-1387. https://doi.org/10.1046/j.1365-294X.2003. 01820.x.

Pérez, T., Naves, J., Vázquez, J.F., Fernández-Gil, A., Seijas, J., Albornoz, J., Revilla, E., Delibes, M., Domínguez, A., 2014. Estimating the population size of the endangered Cantabrian brown bear through genetic sampling. Wildl. Biol. 20, 300-309. https:// doi.org/10.2981/wlb.00069.

Pradel, R., 1996. Utilization of capture-mark-recapture for the study of recruitment and population growth rate. Biometrics 52, 703-709. https://doi.org/10.2307/2532908.

Proctor, M.F., McLellan, B.N., Strobeck, C., Barclay, R.M.R., 2004. Gender-specific dispersal distances of grizzly bears estimated by genetic analysis. Can. J. Zool. 82, 1108-1118. https://doi.org/10.1139/Z04-077.

Proctor, M.F., Paetkau, D., McLellan, B.N., et al., 2012. Population fragmentation and inter-ecosystem movements of grizzly bears in Western Canada and the Northern United States. Wildl. Monogr. 1-46. https://doi.org/10.1002/wmon.6.

Province of British Columbia, 2012. Grizzly bears - environmental reporting BC. URL http://www.env.gov.bc.ca/soe/indicators/plants-and-animals/grizzly-bears.html, Accessed date: 22 October 2017.

Purvis, A., Gittleman, J.L., Cowlishaw, G., Mace, G.M., 2000. Predicting extinction risk in declining species. Proc. R. Soc. Lond. B 267, 1947-1952. https://doi.org/10.1098/ rspb.2000.1234.

R Core Development Team, 2017. R Foundation for Statistical Computing.

Riley, S.J., Nesslage, G.M., Maurer, B.A., 2004. Dynamics of early wolf and cougar eradication efforts in Montana: implications for conservation. Biol. Conserv. 119, 575-579. https://doi.org/10.1016/j.biocon.2004.01.019.

Romain-Bondi, K.A., Wielgus, R.B., Waits, L., Kasworm, W.F., Austin, M., Wakkinen, W., 2004. Density and population size estimates for North Cascade grizzly bears using DNA hair-sampling techniques. Biol. Conserv. 117, 417-428. https://doi.org/10. 1016/j.biocon.2003.07.005.

Schwartz, C.C., Haroldson, M.A., White, G.C., Harris, R.B., Cherry, S., Keating, K.A., Moody, D., Servheen, C., 2006. Temporal, spatial, and environmental influences on the demographics of grizzly bears in the Greater Yellowstone Ecosystem. Wildl. Monogr. 161, 1-68. https://doi.org/10.2193/0084-0173(2006)161[1:TSAEIO]2.0. $\mathrm{CO} ; 2$.

Taberlet, P., Camarra, J., Griffin, S., Uhres, E., Hanotte, O., Waits, L., Dubois-Paganon, C., Burke, T., Bouvet, J., 1997. Noninvasive genetic tracking of the endangered Pyrenean brown bear population. Mol. Ecol. 6, 869-876.

Tumanov, I.L., 1995. Reproductive characteristics of captive European brown bears and growth rates of their cubs in Russia. Ursus 10, 63-65.

Tumendemberel, O., Proctor, M., Reynolds, H., Boulanger, J., Luvsamjamba, A. Tserenbataa, T., Batmunkh, M., Craighead, D., Yanjin, N., Paetkau, D., 2015. Gobi bear abundance and inter-oases movements, Gobi Desert, Mongolia. Ursus 26, 129-142. https://doi.org/10.2192/URSUS-D-15-00001.1.

van Oort, H., Mclellan, B.N., Serrouya, R., 2011. Fragmentation, dispersal and metapopulation function in remnant populations of endangered mountain caribou. Anim. Conserv. 14, 215-224. https://doi.org/10.1111/j.1469-1795.2010.00423.x.

Weber, W., Rabinowitz, A., 1996. A global perspective on large carnivore conservation. Conserv. Biol. 10, 1046-1054.

White, G.C., Burnham, K.P., 1999. Program MARK: survival estimation from populations of marked animals. Bird Study 46, S120-S139. https://doi.org/10.1080/ 00063659909477239.

Whittington, J., Sawaya, M.A., 2015. A comparison of grizzly bear demographic parameters estimated from non-spatial and spatial open population capture-recapture models. PLoS One 10,1-17. https://doi.org/10.1371/journal.pone.0134446.

Wielgus, R.B., Bunnell, F.L., 1994. Sexual segregation and female grizzly bear avoidance of males. J. Wildl. Manag. 58, 405-413.

Woods, J.G., Paetkau, D., Lewis, D., McLellan, B.N., Proctor, M., Strobeck, C., 1999. Genetic tagging of free-ranging black and brown bears. Wildl. Soc. Bull. 27, 616-627. https://doi.org/10.2307/3784082. 